\title{
Anomiopus Westwood (Coleoptera, Scarabaeidae): novas espécies do grupo virescens
}

\author{
Virgínia Luzia Canhedo ${ }^{1}$
}

\begin{abstract}
${ }^{1}$ Bolsista FAPERGS recém-doutor. Museu de Ciências Naturais, Fundação Zoobotânica do Rio Grande do Sul. Caixa Postal 1188, 90001-970 Porto Alegre-RS, Brasil.
\end{abstract}

\begin{abstract}
Aвstract. Anomiopus Westwood (Coleoptera, Scarabaeidae): new species of the virescens group. Three new species of Anomiopus Westwood, 1842 are added to the virescens group: A. lunatipes sp. nov. (Brazil: Amazonas), A. paraguaiensis sp. nov. (Paraguai) and A. tuberifrons sp. nov. (Brazil: Minas Gerais, Mato Grosso do Sul and São Paulo). A key to the species of the group virescens is provided.
\end{abstract}

Keywords. Anomiopus; new species; Neotropical; Scarabaeidae; taxonomy.

Resumo. Três novas espécies de Anomiopus Westwood, 1842 são acrescentadas ao grupo virescens: A. lunatipes sp. nov. (Brasil: Amazonas), A. paraguaiensis sp. nov. (Paraguai) e A. tuberifrons sp. nov. (Brasil: Minas Gerais, Mato Grosso do Sul e São Paulo). Chave para as espécies do grupo virescens é fornecida.

Palavras-Chave. Anomiopus; espécies novas; Neotropical; Scarabaeidae; taxonomia.

O gênero Anomiopus Westwood, 1842 foi revisado por Canhedo (2004), resultando em 7 sinonímias, 23 espécies redescritas e 25 novas espécies descritas. Através do estudo morfológico comparativo, as espécies foram agrupadas em três conjuntos taxonômicos, de acordo com a morfologia da carena-transversa propleural, das metatíbias e dos metatarsômeros: grupo cuprarius, grupo smaragdinus e grupo virescens. As espécies que compõem o grupo virescens totalizam 18 e caracterizam-se por apresentarem carenatransversa propleural de extensão variável, porém, nunca contornando a propleura em sua borda externa em direção ao ápice; meso- e metatíbias estreitas ou alargadas, com lados paralelos ou divergentes; face dorso-lateral das metatíbias sempre com dente transversalmente inserido; meso- e metatarsômeros alargados e emarginados no ápice, pelo menos os artículos I e II. No presente trabalho, três novas espécies são descritas para o grupo virescens.

Os exemplares examinados procedem dos seguintes Museus e coleções particulares: Coleção Fernando Zagury Vaz-de-Mello, Viçosa, MG, Brasil (FVMC); Coleção Howden \& Howden, Ontário, Ottawa, Canadá (HAHC); Museu de Ciências Naturais da Fundação Zoobotânica do Rio Grande do Sul, Porto Alegre, RS, Brasil (MCNZ); Museu de Zoologia da Universidade de São Paulo, São Paulo, SP, Brasil (MZSP); Muséum National d'Histoire Naturelle, Paris, França (MNHN).

As dimensões estão expressas em milímetros, de acordo com a seguinte legenda: CT, comprimento total do corpo; CC, comprimento da cabeça; LC, largura da cabeça; CP, comprimento do pronoto; LP, largura do pronoto; CE, comprimento do élitro; LE, largura do élitro; $\mathrm{C} / \mathrm{L}$, comprimento por largura (chanfradura ocular); $\mathrm{L} / \mathrm{C}$, largura por comprimento (pronoto, esternelo, mesosterno); $\mathrm{C} / \mathrm{Lm}$, relação entre comprimento e largura mínima que separa as mesocoxas (saliência metasternal). A terminologia utilizada nas descrições segue a proposta de CANHEDO (2004), alicerçada em EdMONDS (1972) e GÉNIER (1996).

Anomiopus lunatipes sp. nov.

(Figs. 1-11)

Descrição. Corpo (Fig. 6) robusto, $\mathrm{CT}=8,7 \mathrm{~mm}$, convexo, levemente depresso no dorso. Coloração castanhoavermelhada com reflexos metálicos azul-escuros na cabeça e no pronoto; pigídio e face ventral com reflexos verde-escuros; pernas um pouco mais claras; antenas alaranjadas. Tegumento, da cabeça e pronoto, microestriado, semi-fosco; dos élitros, liso e brilhante; pontos circulares, finos e profundos na cabeça, lados do pronoto, depressão pré-escutelar (Fig. 6), mesosterno, porção anterior da saliência metasternal (Fig. 3) e borda anterior dos urosternitos III-VII (Fig. 5); pontos um pouco maiores, subelípticos e umbilicados no pigídio (Fig. 8) e urosternito VIII (Fig. 5); pontos rasos, umbilicados, alguns com cerdas longas, nos mesepimeros, lados do metasterno e metepisternos (Figs. 3, 4); propleura (Fig. 2) quase que totalmente guarnecida com pontos setígeros; no restante do corpo, pontos finíssimos e rasos. Basisterno, propleura (Fig. 2), mesepimeros, porção central do mesosterno, lados do metasterno e coxas (Figs. 3, 4) com microestrias finas entre os pontos; esternelo (Fig. 2) liso, apenas com pontos setígeros.

Cabeça (Fig. 1) subelíptica; duas intumescências largas, pouco perceptíveis, logo acima dos ramos da sutura frontoclipeal. Borda anterior marginada, a margem moderadamente larga, delimitada por concentração de pontos; escavação central moderadamente rasa; borda clipeal bidenteada: dois dentes medianos subtriangulares, estreitos e alongados, ápices subagudos, levemente divergentes entre si, separados por 
emarginação moderadamente estreita e profunda em forma de U; ângulos externos da escavação central obtusos e largos, não formando dente. Sutura fronto-clipeal com ramos retos, finos, finamente carenados, bifurcados na base; tão distantes entre si, na fronte, quanto o comprimento de cada ramo. Junção clípeo-genal reta. Genas obtusamente anguladas, regiões lateral e anterior subiguais em comprimento. Chanfradura ocular moderadamente larga, alongada, $\mathrm{C} / \mathrm{L}=3$; distância interocular cerca de 4 vezes o comprimento da chanfradura. Área occipital marginada, a margem estende-se até o ângulo superior interno da chanfradura ocular. Clava antenal alargada (Fig. 9).

Protórax (Fig. 6) convexo, ângulos anteriores e posteriores projetados, os anteriores subagudos, os posteriores obtusos; borda anterior com margem completa. Borda lateral marginada; em vista lateral (Fig. 7), com angulosidade obtusa logo abaixo da linha mediana; fossetas pronotais arredondadas, profundas, na direção da angulosidade. Disco pronotal com sulco médiolongitudinal moderadamente raso e largo, marcado no terço posterior, acima da depressão pré-escutelar; esta, muito rasa, apenas indicada. Propleura (Fig. 2) com carena-transversa incompleta, ocupando cerca da metade da largura propleural, a borda externa com fileira de múltiplos pontos setosos, proepisternos subplanos. Esternelo moderadamente curto, estreito, $\mathrm{L} / \mathrm{C}=3$, ápice agudo, sem microestrias e guarnecido com pontos setosos. Mesosterno (Figs. 3, 4) moderadamente curto, estreito, $\mathrm{L} / \mathrm{C}=5$. Sutura meso-metasternal arqueada. Saliência metasternal (Fig. 3) retangular, lados levemente divergentes para o mesosterno, $\mathrm{C} / \mathrm{Lm}=1,3$, largura apical 1,2 vezes a menor largura. Disco metasternal plano com sulco médio-longitudinal muito raso, longo, indicado.

Élitros (Figs. 6, 7) subquadrados, no ápice mais estreitados que na base, lados arqueados; úmeros evidentes. Estrias elitrais finas e profundas, pontuadas, as bordas retas, os pontos finos, moderadamente profundos, distantes um do outro por 3 a 4 vezes seu diâmetro; $3^{\mathrm{a}}$ e $4^{\mathrm{a}}$, $5^{\mathrm{a}}$ e $6^{\mathrm{a}}$ unidas no ápice (Fig. 7); $7^{\mathrm{a}}$ estria incompleta, inicia-se sobre o úmero e mais curta que a $6^{\mathrm{a}}$ em comprimento; $8^{\mathrm{a}}$ e $9^{\mathrm{a}}$ ausentes; $10^{\mathrm{a}}$ justaposta à margem, estende-se desde a base até próximo ao ápice da $6^{\mathrm{a}}$. Interestrias levemente convexas, finamente pontuadas.

Profêmures não-marginados na borda posterior. Meso- e metafêmures (Fig. 11) subelípticos, algo alongados medialmente, finamente marginados nas bordas anterior e posterior da face ventral, esta guarnecida com pontos de cerdas moderadamente longas na metade distal. Protíbias (Fig. 10) subtriangulares, alargadas, constrição basal acentuada; borda interna quase reta; borda externa com três dentes moderadamente largos e alongados nos $2 / 3$ distais; terço proximal, com 4 dentículos, o primeiro largo, os outros estreitos, ápices obtusos; face dorsal sem estria longitudinal e com carena dorsal anterior desde a base até o dente apical. Meso- e metatíbias (Fig. 11) achatadas dorso-ventralmente, subtriangulares, alargadas, constrição basal acentuada, a borda apical sinuosa e com o ângulo interno obliquamente chanfrado; face dorso-lateral moderadamente larga, com dente transversalmente inserido no terço distal (Fig. 6). Metatíbias, no ângulo externo-apical com esporão algo alargado, aspecto foliáceo, um pouco mais longo que o metatarsômero I. Mesoe metatarsômeros (Fig. 11) achatados dorso-ventralmente, mais largos que longos, luniformes; I e II com os ângulos interno e externo subiguais em comprimento; III e IV com ângulo externo projetado; $\mathrm{V}$, subcilíndrico, curto, com um par de garras muito curtas e afiladas.

Urosternitos (Fig. 5) III-VI subiguais em comprimento; VII com 2/3 o comprimento do VI; VIII com 2 vezes o comprimento do VII, a borda posterior reta. Pigídio (Fig. 8) mais largo que longo, convexo, o pré-pigídio levemente sobreposto ao pigídio; sulco médio-longitudinal do pré-pigídio não atinge a borda basal do pigídio.

Dimensões: $\mathrm{CT}=8,7 ; \mathrm{CC}=2,0 ; \mathrm{LC}=3,0 ; \mathrm{CP}=3,2 ; \mathrm{LP}=4,6$; $\mathrm{CE}=4,3 ; \mathrm{LE}=4,6$.

Holótipo fêmea, BRASIL, Amazonas, Rio Javari, E. do Equador (Estirão do Equador) (divisa do Brasil com Peru), X.1958, Oliveira leg. ex-col. Martínez (HAHC).

Discussão. A. lunatipes sp. nov. assemelha-se à A. brevipes (Waterhouse, 1891) e A. laetus (Waterhouse, 1891), por apresentar a área occipital marginada, propleura totalmente guarnecida com pontos setosos, metasterno sub-retangular, dentes protibiais distribuídos nos $2 / 3$ distais, bordas anterior e posterior da face ventral dos meso- e metafêmures finamente marginada, face dorso-lateral das meso- e metatíbias com dente transversalmente inserido logo abaixo do terço distal. Diferencia-se de ambas pelo maior comprimento, robustez, clava antenal mais alargada, formato luniforme acentuado dos meso- e metatarsômeros I-IV, ausência de estria longitudinal na face dorsal das protíbias, esternelo e urosternitos lisos, sem microestrias e pela pontuação dos lados do metasterno.

\section{Anomiopus paraguaiensis sp. nov.}

(Figs. 12-28)

Descrição. Corpo (Fig. 19) alongado, delgado, levemente deprimido dorsalmente. Coloração castanho-escura, dorsalmente metálica, verde-escura, às vezes com reflexos cúpreos, mais homogênea e evidente na cabeça, pronoto e pigídio (um dos espécimens com reflexos azul-escuros); face ventral, castanho-avermelhada. Antenas amarelas. Tegumento, no geral, brilhante, fina e densamente pontuado, os pontos moderadamente profundos, distantes um do outro por 1 a 2 vezes seu diâmetro, mais evidentes no pronoto; pigídio (Figs. 21, 22) e urosternito VIII (Fig. 20) com pontuação um pouco mais esparsa. Propleura, esternelo (Fig. 14), porções basal e lateral do mesosterno, região apical da saliência metasternal, mesepimeros, metepisternos, lados do metasterno, coxas (Figs. 15, 18), pré-pigídio (Figs. 21, 22), urosternitos III-VI, porção apical do urosternito VIII (Fig. 20), face dorsal das protíbias (Figs. 24, 25), ventral das metatíbias (Fig. 28) e porção apical do pigídio microrreticulados (Figs. 21, 22). Proepimeros, esternelo (Fig. 14), porção central do mesosterno, mesepimeros, 
porção anterior da saliência metasternal, metepisternos, lados do metasterno (Figs. 15, 18) e borda anterior dos urosternitos III-VII (Fig. 20) com alguns pontos providos de cerdas longas.

Cabeça (Figs. 12,13) subelíptica, vértice subplano e com depressão leve na fronte entre os ramos da sutura frontoclipeal. Borda anterior finamente marginada; escavação central moderadamente rasa e larga; borda clipeal bidenteada: dois dentes medianos subtriangulares, moderadamente curtos e estreitos, paralelos entre si, separados por emarginação profunda em forma de U e com um ponto setoso na base, os ângulos externos da escavação central apenas arredondados; no macho dentes levemente mais curtos e largos que na fêmea. Sutura fronto-clipeal com ramos finos e rasos, retos na metade distal, levemente sinuosos e mais profundos na metade proximal; distância entre os ramos na fronte subigual ao comprimento de cada ramo. Genas arqueadas, regiões anterior e lateral subiguais em comprimento. Junção clípeo-genal nãoentalhada. Área occipital com carena completa (marginada). Chanfradura ocular estreita e alongada $\mathrm{C} / \mathrm{L}=6$, distância interocular cerca de 7 vezes o comprimento da chanfradura. Clava antenal alargada (Fig. 23).

Protórax (Fig. 19) convexo, com suave depressão no pronoto; ângulos anteriores sub-retos e os posteriores, obtusos. Borda anterior com margem completa. Borda lateral marginada; em vista lateral arqueada medialmente no macho (Fig. 16), levemente angulada na fêmea (Fig. 17); fossetas pronotais arredondadas e rasas, indicadas no macho, mais evidentes na fêmea. Disco pronotal com sulco médiolongitudinal (inconspícuo na fêmea, mais acentuado no macho) que não atinge a borda posterior; a depressão pré-escutelar rasa, inconspícua. Propleura (Fig. 14) com carena-transversa incompleta, ocupando cerca de $1 / 3$ da largura propleural; borda lateral com fileira simples de pontos. Proepisternos com depressão central ampla e rasa, guarnecidos com pontos esparsos de cerdas longas. Esternelo moderadamente curto, estreito, $\mathrm{L} / \mathrm{C}=2,2$, ápice agudo. Mesosterno (Figs. 15, 18) moderadamente curto, estreito, $\mathrm{L} / \mathrm{C}=4,2$. Sutura mesometasternal levemente arqueada. Saliência metasternal (Fig. 15) trapezoidal, estreita, $\mathrm{C} / \mathrm{Lm}=6$, lados fortemente divergentes para o mesosterno, largura apical 4,5 vezes a menor largura, levemente gibosa anteriormente. Disco metasternal longo, subplano, a distância entre as mesocoxas e metacoxas maior que o comprimento da mesocoxa; sulco médio-longitudinal longo, raso, central.

Élitros (Figs. 16, 17, 19) sub-retangulares, bordas laterais levemente arqueadas, úmeros levemente projetados. Estrias finas e algo profundas, as bordas retas, com pontos finos, distantes um do outro por 3 a 4 vezes seu diâmetro; $4^{\mathrm{a}}$ e $5^{\mathrm{a}}$ estrias unidas no ápice (na fêmea, mais curtas que a $6^{\mathrm{a}}$ ); $7^{\mathrm{a}}$ estria incompleta, inicia-se abaixo do úmero e mais curta que a $6^{\mathrm{a}} ; 8^{\mathrm{a}}$ apenas indicada na porção distal; $9^{\mathrm{a}}$ estria ausente; $10^{\mathrm{a}}$ estria justaposta à margem, inicia-se na direção do úmero e estende-se até próximo ao ápice da $6^{\mathrm{a}}$. Interestrias levemente convexas, com pontos finíssimos, esparsos.

Profêmures (Fig. 26) não-marginados na borda posterior da face ventral. Meso- e metafêmures (Fig. 28) subelípticos, alargados medialmente, não-marginados na borda anterior da face ventral. Protíbias (Figs. 24, 25) subtriangulares, alargadas, a constrição basal acentuada, a borda interna reta; borda externa, nos $2 / 3$ distais, com 3 dentes moderadamente curtos e largos, de ápices arredondados (o mediano mais largo que o apical na fêmea; o apical mais robusto que o mediano no macho) e no terço proximal com 2-3 dentículos largos de ápices obtusos; face dorsal sem estria longitudinal e sem carena dorsal anterior. Meso- e metatíbias achatadas dorso-ventralmente, subtriangulares, a constrição basal atenuada, na face dorsolateral com dente transversalmente inserido logo abaixo da linha mediana (Fig. 27); borda apical suavemente emarginada medialmente, o ângulo interno obliquamente chanfrado. Mesoe metatarsômeros (Figs. 19, 28) subtriangulares, curtos, justapostos, decrescentes em largura em direção ao ápice, o ângulo externo levemente projetado, a borda apical sutilmente arqueada; I, um pouco mais curto que o II; V, subigual ao IV em comprimento e com um par de garras afiladas, cerca de $1 / 3$ o comprimento do tarsômero.

Urosternitos (Fig. 20) III-VI subiguais em comprimento e com uma fileira de pontos na borda anterior; VI, metade do comprimento do VII; VIII, cerca de 3 vezes o comprimento do VII e guarnecido com pontos algo mais grossos e profundos. Pigídio levemente convexo, mais largo que longo, mais alongado no macho (Fig. 21) que na fêmea (Fig. 22); sulco médio-longitudinal do pré-pigídio atinge a borda basal do pigídio.

Dimensões macho/fêmea, respectivamente: $\mathrm{CT}=4,8 / 4,8$; $\mathrm{CC}=0,9 / 0,9 ; \mathrm{LC}=1,2 / 1,4 ; \mathrm{CP}=1,7-1,8 ; \mathrm{LP}=1,7 / 1,85 ; \mathrm{CE}=2,2$ 2,$4 ; \mathrm{LE}=1,8 / 1,9$.

Holótipo macho, PARAGUAI, San Pedro, Rio Yapané, Cororó, XI.1979, ex-Col. Martínez (HAHC). Parátipo fêmea, San Pedro, Cororó, II. 1979, M. Viana leg., ex- Col. A. Martínez, com etiqueta $A$. pereirai Martínez det. 1993 (HAHC).

Discussão. A. paraguaiensis sp. nov. assemelha-se à $A$. pereirai (Martínez, 1955) pelo metasterno e morfologia dos meso- e metatarsômeros. Diferencia-se pelo tamanho menor $(\mathrm{CT}=4,8)$ e forma proporcionalmente mais cilíndrica; metasterno mais alongado e saliência metasternal mais estreita medialmente, $\mathrm{C} / \mathrm{Lm}=6$; pronoto com sulco médio-longitudinal inconspícuo e chanfradura ocular bem mais estreita $(\mathrm{C} / \mathrm{L}=6)$. A. pereirai, além de ser maior em comprimento $(\mathrm{CT}=5,8-8,1)$, apresenta chanfradura ocular larga $(\mathrm{C} / \mathrm{L}=2,0)$, o pronoto com sulco médio-longitudinal bem marcado e relação $\mathrm{C} / \mathrm{Lm}=3,6$ na saliência metasternal.

\section{Anomiopus tuberifrons sp. nov.}

(Figs. 29-45)

Descrição. Corpo (Figs. 35, 36) alongado, robusto, levemente depresso dorsalmente. Coloração castanho-escura, dorsalmente verde-metálica, mais evidente e homogênea na cabeça, pronoto e pigídio; cabeça com reflexos cúpreos. Tegumento da cabeça (Figs. 29, 30) e pronoto (Figs. 35, 36) 

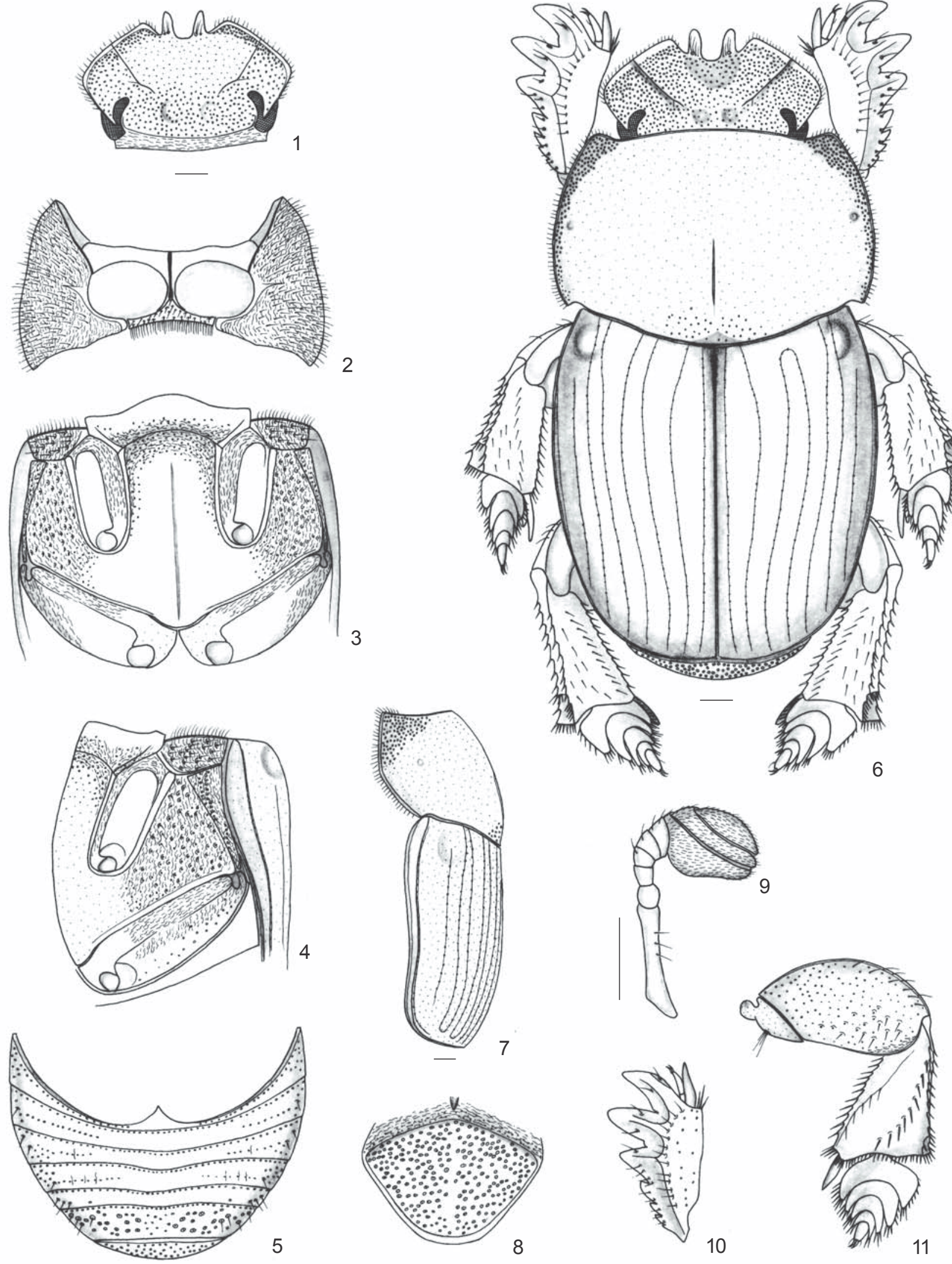

Figs. 1-11. Anomiopus lunatipes sp. nov. Holótipo fêmea. 1, cabeça, frontal; 2, protórax, ventral; 3-4, meso- e metatórax: 3, ventral, 4, lateral; 5, abdome, ventral; 6, habitus; 7, protórax e élitro, lateral; 8, pigídio, frontal; 9, antena; 10, protíbia, dorsal; 11, perna posterior, ventral. Figs. $1-6,8 ; 9-11$, na mesma escala. Barra $=0,5 \mathrm{~mm}$. 
algo irregular, às vezes com pequenas rugas finas, longitudinais; pontuação fina e densa; pontos evidentes e profundos no pronoto (próximos entre si) e no pigídio (algo mais esparsos, maiores e umbilicados) (Figs. 38, 39); pontos finos e profundos no esternelo (Fig. 31), mesosterno (Figs. 32, 33) e urosternito VIII (Fig. 34); pontos com cerdas longas nos proepisternos e borda externa da propleura (Fig. 31), mesepimeros, porção anterior da saliência metasternal (Figs. 32, 33), lados dos urosternitos (Fig. 34), região central da face ventral dos mesoe metafêmures (Fig. 40) e face ventral dos profêmures; nos lados dos urosternitos IV-VI (Fig. 34) concentração de pontos finos em ambos os sexos. Basisterno, propleura, esternelo (Fig. 31), mesosterno, mesepimeros, metepisternos, lados do metasterno, coxas (Figs. 32, 33) e pré-pigídio (Figs. 38, 39) com microestrias finas entre os pontos; face dorsal das protíbias (Figs. 41, 42) finissimamente microrreticulada.

Cabeça (Figs. 29, 30) subelíptica; fronte e vértice convexos; entre os ramos da sutura fronto-clipeal, depressão muito leve; na base de cada ramo da sutura fronto-clipeal, uma intumescência larga, arredondada, evidente; o tegumento, em toda essa região, levemente sub-rugoso (exceto no holótipo, no qual o tegumento é apenas levemente irregular). Borda anterior com margem estreita, pouco conspícua, mais evidente nas fêmeas; próximo à borda, alguns sulcos longitudinais finíssimos. Borda clipeal 4-denteada: dois dentes medianos, subtriangulares, longos e estreitos, paralelos entre si, ápices subagudos (dentes mais longos nas fêmeas), separados por emarginação moderadamente profunda em forma de U, curvados para cima, na base com um ponto largo provido de cerdas; dois dentes laterais, subtriangulares, curtos e largos, ápices obtusos, nos ângulos externos da escavação central. Sutura fronto-clipeal com ramos finos e algo profundos, finamente carenados, retos na porção distal, levemente arqueados na proximal; na base de cada ramo, uma intumescência larga, subtriangular, arredondada no ápice; distância entre os ramos, na fronte, subigual ao comprimento de cada ramo. Junção clípeo-genal levemente entalhada. Genas levemente arqueadas medialmente, algo angulosas nas fêmeas. Área occipital com carena completa. Chanfradura ocular moderadamente larga, $\mathrm{C} / \mathrm{L}=3$, marginada na borda interna em continuação à margem da área occipital; distância interocular cerca de 7 vezes o comprimento da chanfradura. Clava antenal alargada (Fig. 43).

Protórax (Figs. 35, 36) convexo, os lados bastante defletidos; ângulos anteriores e posteriores discretos, os anteriores retos, os posteriores obtusos; depressão préescutelar pequena e rasa; borda anterior com margem completa. Borda lateral marginada; em vista lateral (Fig. 37) fortemente arqueada logo acima da metade posterior; fossetas pronotais largas, algo irregulares, moderadamente profundas. Disco pronotal (Figs. 35, 36) com sulco médio-longitudinal bem marcado, moderadamente profundo, logo abaixo da linha mediana, não-atingindo a borda posterior. Propleura (Fig. 31) com carena-transversa incompleta, tênue, ocupando $c a$. 1/3 da largura propleural; borda externa com fileira simples de pontos; proepisternos planos com pontos esparsos providos de cerdas longas. Esternelo curto, estreito, $\mathrm{L} / \mathrm{C}=4$, ápice agudo. Mesosterno (Figs. 32, 33) moderadamente curto, moderadamente estreito, $\mathrm{L} / \mathrm{C}=7,3$. Sutura meso-metasternal levemente arqueada. Saliência metasternal (Fig. 32) trapezoidal, $\mathrm{C} / \mathrm{Lm}=4,0$, lados fortemente divergentes para o mesosterno, largura apical 3,6 vezes a menor largura, subplana. Disco metasternal plano, alongado, a menor distância entre as mesocoxas e metacoxas subigual ao comprimento da mesocoxa; sulco médio-longitudinal longo, estreito, moderadamente profundo, desde a porção mediana da saliência até logo acima da borda posterior.

Élitros (Figs. 35-37) sub-retangulares, levemente mais estreitos no ápice que na base, bordas externas sutilmente arqueadas; úmeros discretos. Estrias finas, pouco profundas, bordas retas, pontuadas, pontos bem marcados, um pouco maiores que a largura da estria, distantes um do outro por 1 a 2 vezes seu diâmetro; $7^{\mathrm{a}}$ estria incompleta, inicia-se sobre o úmero e subigual à $6^{\mathrm{a}}$ em comprimento; $8^{\mathrm{a}}$ apenas sutilmente indicada na porção posterior; $9^{\mathrm{a}}$ ausente; $10^{\mathrm{a}}$ justaposta à margem, finíssima, desde a base até próximo ao ápice da $6^{\mathrm{a}}$. Interestrias subplanas, pontuação densa, muito fina e rasa.

Profêmures não-marginados na borda posterior da face dorsal. Meso- e metafêmures (Fig. 40) subelípticos, algo alargados medialmente, robustos, não-marginados na borda anterior da face ventral. Protíbias (Figs. 41, 42) subtriangulares, alargadas desde a base até o ápice, constrição basal acentuada, em ângulo reto; borda interna emarginada medialmente, levemente arqueada no terço proximal; borda externa com três dentes moderadamente longos e largos, ápices subagudos, distribuídos nos 2/3 distais (dente apical levemente mais robusto no macho e o mediano um pouco mais largo na fêmea); no terço proximal, três dentículos largos, ápices subagudos; face dorsal sem estria longitudinal, carena dorsal anterior discreta, desde a base até o dente mediano. Meso- e metatíbias (Figs. 35, 36, 40) achatadas dorso-ventralmente, subtriangulares, algo alargadas, a constrição basal acentuada; face dorso-lateral alargada, com dente transversalmente inserido na porção mediana (Fig. 44); borda apical reta; metaesporão robusto, subigual ao comprimento dos metatarsômeros I e II juntos, levemente espatuliforme (Fig. 45). Meso- e metatarsômeros (Figs. 40, 45) achatados dorsoventralmente, subtriangulares, mais largos que longos, I-IV com ângulo externo projetado, justapostos, decrescentes em largura e comprimento em direção aos tarsômeros apicais; V, subigual ao IV em comprimento e com um par de garras afiladas ca. metade do comprimento do tarsômero.

Urosternitos (Fig. 34) III-VI subiguais em comprimento; VII $c a$. metade do comprimento do VI; VIII $c a$. duas vezes o comprimento do VII. Pigídio (Figs. 38, 39) mais largo que longo, algo mais alongado no macho que na fêmea, convexo; sulco médio-longitudinal do pré-pigídio atinge a borda basal do pigídio.

Dimensões machos/fêmeas, respectivamente: $\mathrm{CT}=6,3-7,4$ / $7,5-8,2 ; \mathrm{CC}=1,3-1,4 / 1,3-1,4 ; \mathrm{LC}=1,9-2,0 / 2,2-2,5 ; \mathrm{CP}=2,2-2,6 /$ $2,5-2,9 ; \mathrm{LP}=2,7-3,1 / 3,4-3,6 ; \mathrm{CE}=3,1-3,4 / 3,7-3,9 ; \mathrm{LE}=2,9-3,3 /$ $3,5-3,7$. 

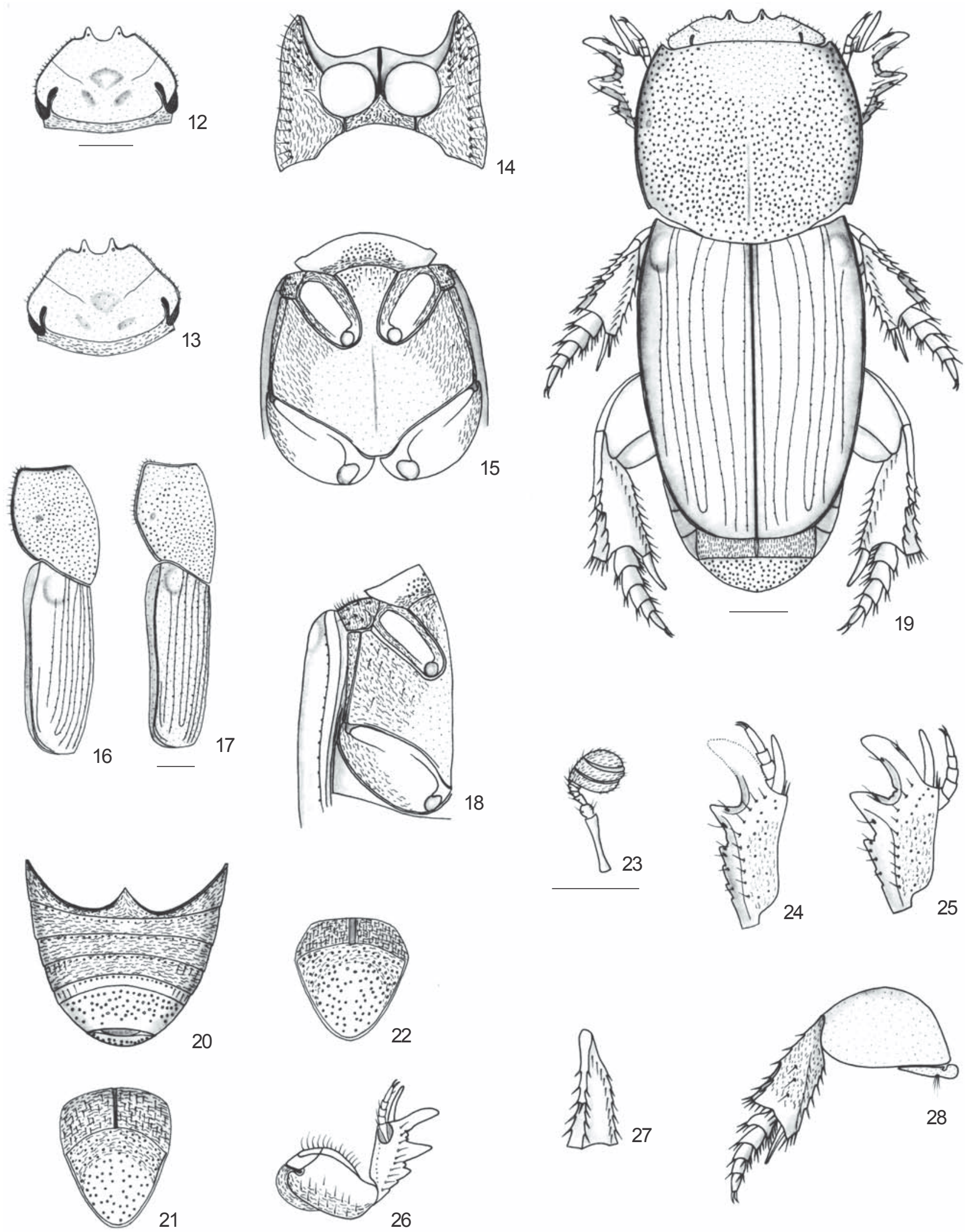

Figs. 12-28. Anomiopus paraguaiensis sp. nov. Holótipo macho, parátipo fêmea. Cabeça, frontal: 12, macho, 13, fêmea; 14, protórax, ventral; meso- e metatórax: 15, ventral, 18, lateral; protórax e élitro, lateral: 16, macho, 17, fêmea; 19, habitus, parátipo fêmea; pigídio, frontal: 21, macho, 22, fêmea; 23, antena; protíbia dorsal: 24, macho, 25, fêmea; 26, perna anterior, ventral; 27, metatíbia, face dorso-lateral; 28, perna posterior, ventral. Figs. 12-15, 18-22 e 26-28; 16 e 17; 23-25, na mesma escala, respectivamente. Barra $=0,5$ mm. 
Holótipo macho, BRASIL, São Paulo, Batatais, XI.1945, ex-col. Ginásio São José, Pe. Pereira leg., ex-col. Martínez (HAHC). Parátipo macho, Mato Grosso do Sul, Campo Grande, 07.III.1979, W.W. Koller col. (MCNZ, ex-FVMC). Parátipo fêmea, Minas Gerais, Campos Gerais, ex-Musaeo E. Harold, ex-col. R. Oberthür (MNHN). Parátipo fêmea, PARAGUAI, San Pedro, Rio Yapané, Cororó, XI.1979, ex-col. Martínez (MZSP, ex- HAHC).

Discussão. A. tuberifrons sp. nov. assemelha-se à $A$. pereirai Martínez, 1955) pelo formato dos meso- e metatarsômeros, metasterno alongado e chanfradura ocular larga. Diferencia-se pelo tegumento irregular da cabeça e pronoto (por vezes sub-rugoso na área fronto-clipeal da cabeça e central do disco pronotal); fronte e vértice convexos com intumescência conspícua e larga na base de cada ramo da sutura fronto-clipeal; chanfradura ocular marginada na borda interna; meso- e metatíbias subtriangulares com borda apical reta e metaesporão robusto, espatuliforme (em $A$. pereirai o tegumento é muito liso e brilhante, a área frontevértice é plana com depressão leve entre os ramos da sutura fronto-clipeal; chanfradura ocular não-marginada na borda interna; ramos da sutura fronto-clipeal sem intumescência na base; meso- e metatíbias sub-retangulares, metaesporão acuminado).

Para incluir as três novas espécies faz-se necessário substituir os itens 1 a 6 , na chave do grupo virescens (CANHEDO 2004), pelos itens 1 a 9 no presente trabalho:

1. Face dorso-lateral das metatíbias com crista de dentículos ou dente transversalmente inserido no terço distal (Fig. 6)

Face dorso-lateral das metatíbias apenas com dente transversalmente inserido medialmente ou quase medialmente (Figs. 27, 44) .5

2(1). Borda anterior da face ventral dos metafêmures com margem larga; crista de dentículos no terço distal da face dorso-lateral das metatíbias; protíbias com dentes distribuídos no terço apical; borda clipeal com dentes medianos fortemente divergentes, separados por emarginação larga e rasa. ARGENTINA ................. A.juanae (Martínez, 1955)

Borda anterior da face ventral dos metafêmures com margem estreita, justaposta à borda (Fig. 11); apenas um dente transversalmente inserido no terço distal da face dorso-lateral das metatíbias; protíbias com dentes distribuídos nos $2 / 3$ apicais (Fig. 10); borda clipeal com dentes medianos subparalelos separados por emarginação estreita e profunda em forma de U (Fig. 1)....

3(2). Metatarsômeros I-IV, curtos e largos, luniformes, ângulos interno e externo projetados, o externo maior (Fig. 11); face dorsal das protíbias sem estria longitudinal (Fig. 10); forma grande, robusta (Fig. 6). BRASIL (Amazonas) ........... A. lunatipes sp. nov.
Metatarsômero I, luniforme, ângulos interno e externo igualmente projetados; II-IV, mais longos que largos, apenas o ângulo externo projetado; face dorsal das protíbias com estria longitudinal; formas pequenas a medianas $(\mathrm{CT}=5,8-8,5) \ldots \ldots \ldots \ldots \ldots \ldots . . .4$

4(3). Fronte com elevação transversa entre os ramos da sutura fronto-clipeal; cabeça e pronoto com pontuação fina, mais grossa somente nos ângulos anteriores do pronoto. EQUADOR, PERU, COLÔMBIA, BRASIL (Amazonas) A. brevipes (Waterhouse, 1891)

Fronte com duas intumescências pequenas, arredondadas, justapostas à cada ramo da sutura fronto-clipeal; cabeça e pronoto com pontuação moderadamente grossa. BRASIL (Pará, Amazonas, Acre) ........................ A. laetus (Waterhouse, 1891)

5(1). Meso- e metatarsômeros I-IV alargados, justapostos (Figs.19, 28, 35, 36, 40, 45), (formando estrutura compacta), a borda apical emarginada em arco, o ângulo externo projetado ........................................ 6

Meso- e metatarsômeros com outra conformação ... 10

6(5). Élitros castanho-escuros, com mancha alaranjada ampla e central, no disco. BRASIL (Amazonas) A. pictus (Harold, 1862)

Élitros com coloração uniforme 7

7(6). Metasterno curto, a menor distância entre as mesoe metacoxas, no disco, subigual à metade do comprimento das mesocoxas; sutura mesometasternal reta; face dorso-lateral das metatíbias muita estreita, a metade distal apenas pouco mais larga que a proximal, o dente transversal quase imperceptível. EQUADOR, PERU ....................... A. intermedius (Waterhouse, 1891)

Metasterno alongado, a menor distância entre as mesoe metacoxas, no disco, subigual ao comprimento total das mesocoxas (Figs. 15, 32); sutura mesometasternal levemente arqueada; face dorso-lateral das metatíbias moderadamente estreita, a metade distal alargada, a largura quase o dobro da metade proximal, o dente transversal conspícuo .8

8(7). Chanfradura ocular muito estreita, $\mathrm{C} / \mathrm{L}=6$ (Figs. 12, 13); formas pequenas e delicadas $(\mathrm{CT}=4,8)$ (Fig. 19). PARAGUAI (San Pedro)

A. paraguaiensis sp. nov.

Chanfradura ocular larga, $\mathrm{C} / \mathrm{L}=2,0-3,0$; formas medianas a grandes, robustas $(\mathrm{CT}=5,8-8,2)$ (Figs. $29,30)$ 9

9(8). Tegumento muito liso e brilhante; cabeça plana no vértice e apenas com depessão leve na área frontal. BRASIL (Pará, Maranhão, Bahia, Rondônia, Mato 

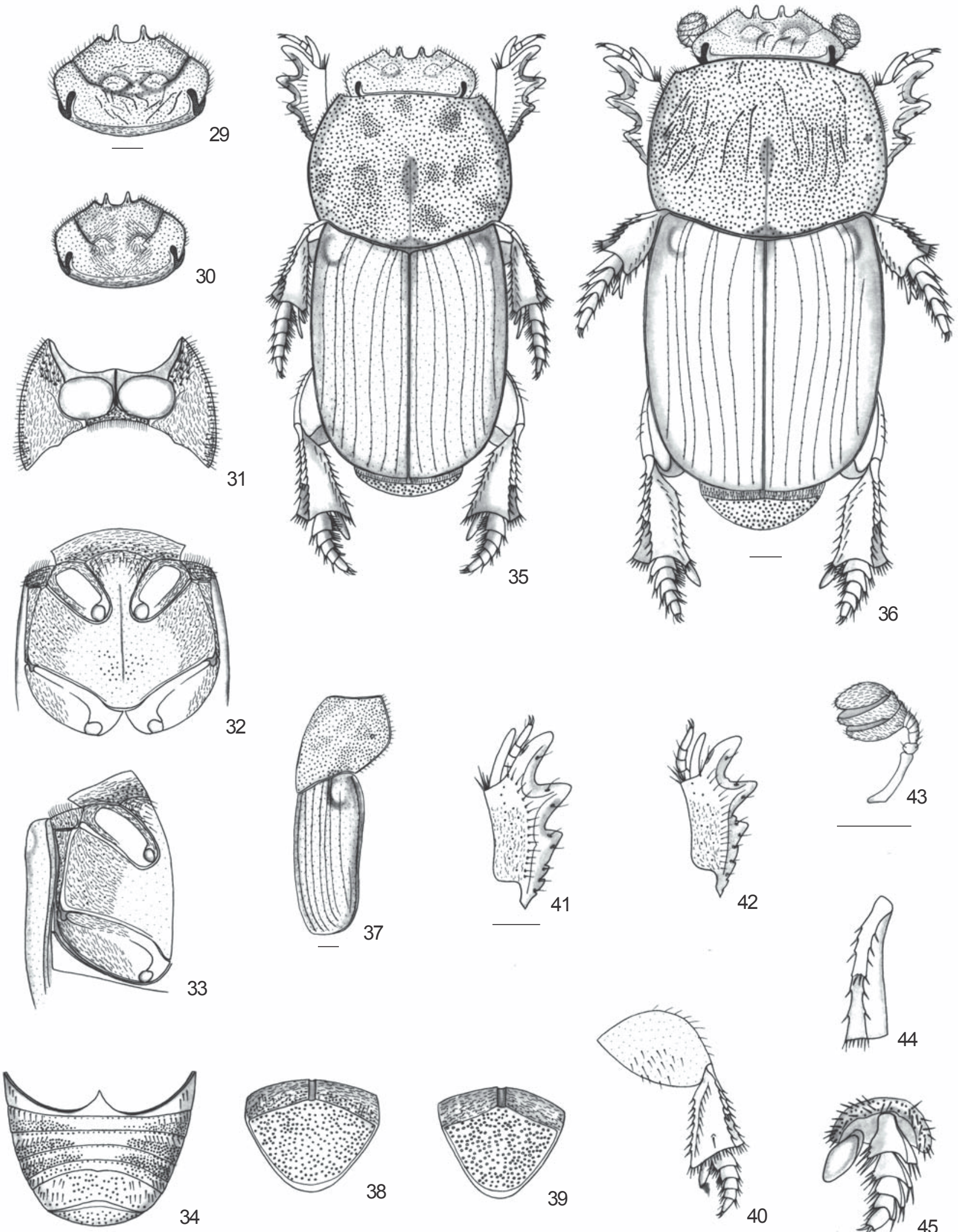

Figs. 29-45. Anomiopus tuberifrons sp. nov. Holótipo macho, parátipo fêmea. Cabeça, frontal: 29, macho, 30, fêmea; 31, protórax ventral; meso- e metatórax: 32, ventral, 33, lateral; 34, abdome, ventral; habitus: 35, holótipo macho, 36, parátipo fêmea; 37, protórax e élitro, lateral; pigídio: 38, fêmea, 39, macho; 40, perna posterior, ventral; protíbia: 41, fêmea, 42, macho; 43, antena; 44, metatíbia, face dorso-lateral; 45, metatarsômeros, frontal. Figs. 29-36 e 38-40; 41, 42, 44 e 45, na mesma escala, respectivamente. Barra $=0,5 \mathrm{~mm}$. 
Grosso, Goiás, Distrito Federal, Minas Gerais, Mato Grosso do Sul, São Paulo, Paraná)

A. pereirai (Martinez, 1955)

Tegumento irregular na cabeça e pronoto (Figs. 29, 30, $35,36)$, com algumas rugas e/ou depressões; cabeça convexa no vértice e com intumescência arredondada larga e evidente, na base de cada ramo da sutura fronto-clipeal (Figs. 29, 30). BRASIL (Minas Gerais, Mato Grosso do Sul, São Paulo) A. tuberifrons sp. nov.

10(5). Saliência metasternal retangular, $\mathrm{C} / \mathrm{Lm}=1,3-2,1$, a largura apical 1,2-1,9 vezes a menor largura ....... 11 Saliência metasternal trapezoidal, $\mathrm{C} / \mathrm{Lm}=2,2-4,0$, a largura apical 2,0-3,3 vezes a menor largura ....... 15

11(10). Meso- e metatarsômeros I-IV luniformes, largura cerca de 4 vezes o comprimento, borda apical emarginada em arco; I, com ângulos igualmente projetados; IIIV com ângulo externo mais longo que o interno. BRASIL (Rondônia, Mato Grosso, Goiás, Minas gerais, Espírito Santo, São Paulo), BOLÍVIA, PARAGUAI ................. A virescens Westwood, 1842

Meso- e metatarsômeros I-IV, subtriangulares, moderadamente alargados ou pouco mais longos que largos, borda apical sinuosamente emarginada ou levemente emarginada em arco, o ângulo externo mais longo que o interno 12

12(11). Fronte com elevação central ampla, subtriangular; vértice, às vezes, com duas depressões alongadas; tegumento, na cabeça, sub-rugoso, com pontuação densa, fina no vértice, mais grossa e evidente na porção anterior; meso- e metatíbias retangulares, estreitas, alongadas. BRASIL (Minas Gerais, Rio de Janeiro, São Paulo) .... A. chalceus (Harold, 1867)

Fronte com outro aspecto; meso- e metatíbias subtriangulares . 13

13(12). Pronoto com sulco médio-longitudinal longo e profundo; lados do metasterno com pontos finos. GUIANA FRANCESA, BRASIL (Pará) .

A. aequalis (Waterhouse, 1891)

Pronoto sem sulco médio-longitudinal; lados do metasterno com pontos moderadamente grossos .

14

14(13). Borda clipeal 4-denteada, os dentes laterais com ápices agudos. BRASIL (Pará, Amazonas, Maranhão, Mato Grosso) ........ A. simplex (Waterhouse, 1891)

Borda clipeal 6-denteada, os dentes laterais com ápices arredondados. BRASIL (Bahia, Goiás, Minas Gerais, Espírito Santo, Rio de Janeiro, São Paulo, Rio Grande do Sul), PARAGUAI

A. nigrocoeruleus (Martínez, 1955)
15(10). Cabeça com elevação transversa na fronte, em forma de $\mathrm{V}$ invertido, entre as áreas depressas do clípeo e do vértice. GUIANA FRANCESA, BRASIL (Amapá, Amazonas, Mato Grosso do Sul) A. myrmidon (Westwood, 1842)

Cabeça sem elevação transversa na fronte . .16

16(15). Área occipital sem carena (não-marginada) ou com carena incompleta, restrita aos ângulos externos ou à borda interna da chanfradura ocular .......... 17 Área occipital com carena completa (marginada) .... 20

17(16). Saliência metasternal com lados fortemente divergentes para o mesosterno, a largura apical o triplo da menor largura e com pontos setosos apicalmente. VENEZUELA, BRASIL

A. puncticollis (Harold, 1862)

Saliência metasternal com lados divergentes para o mesosterno, a largura apical subigual ao dobro da menor largura e sem pontos setosos apicalmente

18

18(17). Borda clipeal 6-denteada; chanfradura ocular muito estreita, $\mathrm{C} / \mathrm{L}=5$. BRASIL (Goiás, Minas Gerais, Rio de Janeiro) ............... A. pumilius Canhedo, 2004

Borda clipeal bi ou 4-denteada; chanfradura ocular moderadamente estreita $\mathrm{C} / \mathrm{L}=3,0-3,3$ 19

19(18). Borda clipeal bidenteada, os ângulos externos da escavação central apenas arredondados; metafêmures alargados; borda apical das metatíbias obliquamente truncada, o ângulo interno pouco projetado. BRASIL (Pará, Amazonas, Acre, Espírito Santo) A. andrei Canhedo, 2004

Borda clipeal 4-denteada, os dentes externos com ápices agudos; metafêmures alongados, estreitos; borda apical das metatíbias sinuosa, o ângulo interno projetado. PERU ..... A. gilli Canhedo, 2004

20(16). Cabeça com pontuação grossa e densa; metafêmures robustos, algo alargados; metatarsômeros tão largos quanto longos ou curtos e alargados, I e II subiguais em comprimento. GUIANA FRANCESA, BRASIL (Amapá, Pará, Amazonas, Pernambuco, Mato Grosso) ............... A. parallelus (Harold, 1862)

Cabeça com pontuação fina e esparsa; metafêmures alongados; metatarsômeros mais longos que largos, o comprimento do I igual a 1,3-1,8 vezes o do II. BRASIL (Amapá, Pará, Amazonas, Acre) A. zaguryi Canhedo, 2004

Agradecimentos. À FAPERGS pela bolsa de estudos, à Fundação Zoobotânica do Rio Grande do Sul pela concessão de uso dos equipamentos e, em especial, à Dra. Maria Helena Mainieri Galileo (MCNZ) pela supervisão, leitura crítica e sugestões. 


\section{REFERÊNCIAS}

Canhedo, V. L. 2004. Revisão taxonômica do gênero Anomiopus Westwood, 1842 (Coleoptera, Scarabaeidae, Scarabaeinae, Dichotomiini). Arquivos de Zoologia 37(2): 141-294.

Edmonds, W. D. 1972. Comparative skeletal morphology, systematics and evolution of the Phanaeina dung beetles (Coleoptera, Scarabaeidae). The University of Kansas Science Bulletin 49(11): 731-874.

GÉNIER, F. 1996. A revision of the Neotropical genus Ontherus Erichson (Coleoptera: Scarabaeidae: Scarabaeinae). Memoirs of the Entomological Society of Canada (170): 1-169. 